\title{
TRANSFORMAÇÃO DIGITAL E O ACESSO A INTERNET COMO DIREITO FUNDAMENTAL
}

\section{DIGITAL TRANSFORMATION AND INTERNET ACCESS AS A FUNDAMENTAL RIGHT}

\author{
Glauco Marcelo Marques ${ }^{1}$
}

RESUMO: O presente artigo abordará a consonância entre a era do conhecimento com suas novas tecnologias, diante dos novos desafios dos direitos fundamentais sociais coletivos, reconhecendo o acesso à internet como um destes. Atualmente vivemos na era da comunicação, a chamada Sociedade da Informação, nascida em meados dos anos 70, na denominada Quarta Revolução Industrial, na qual o conhecimento é o centro do poder político, social e econômico. O desafio da humanidade é a sobrevivência do indivíduo, que doravante necessitará do acesso à internet em nome da inclusão digital.

PALAVRAS- CHAVES: 1 Transformação digital; 2 Acesso a internet; 3 Internet como direito fundamental; 4 Inclusão Digital; 5 Direito e Tecnologia.

\begin{abstract}
This article will address the consonance between the era of knowledge and its new technologies, facing the new challenges of collective fundamental social rights, recognizing access to the internet as one of these. We currently live in the age of communication, the so-called Information Society, born in the mid-1970s, in the so-called Fourth Industrial Revolution, in which knowledge is the center of political, social and economic power. Humanity's challenge is the survival of the individual, who will henceforth need access to the internet in the name of digital inclusion.
\end{abstract}

\footnotetext{
${ }^{1}$ Mestrando em Direito e Estado na Era Digital do UNIVEM (2020). Pós Graduado em Direito Tributário na Univem em Marilia/SP. Graduado pela Universidade de Marília - UNIMAR. Advogado desde 2000. Contato:glaucomarques@aconsel.net. Endereço para acessar este CV: http://lattes.cnpq.br/5781231282827792
} 
KEYWORD: 1 Digital transformation; 2 Internet access; 3 Internet as a fundamental right; 4 Digital Inclusion; 5 Law and Technology.

\section{IINTRODUÇÃO}

O Direito é um constante caminhar, sendo o movimento do neoconstitucionalismo uma evolução constitucional que cresce no Brasil. O constitucionalismo, com origem na antiguidade clássica, que se traduzia pela limitação do poder do Estado, ficou para trás, enquanto o neoconstitucionalismo, entendido como a busca de uma reaproximação entre direito e moral e preocupação com a justiça, fortalece-se.

O chamado neoconstitucionalismo se enquadra como uma doutrina do Direito em que a Constituição está no centro do ordenamento jurídico. Essa corrente de pensamento se contrapõe ao constitucionalismo anterior que, baseado em uma visão meramente positivista, defendia a interpretação dura e fria das normas constitucionais.

Entramos na era do conhecimento, vivendo o fenômeno da transformação digital, o mundo como conhecíamos no século XX findou-se. Na era digital, a vida é acelerada, mídias sociais, globalização, inteligência artificial, internet das coisas, big data, e outras novidades, são realidades que chegaram com muita força ao Brasil. A transformação da Sociedade da Informação é caracterizada pela mudança do processo analógico para o digital, do linear para o exponencial, do tradicional para o disruptivo, de forma a modernizar nosso modo de vida.

Ocorre que, paradoxalmente, o cenário social brasileiro ainda vive no século $\mathrm{XX}$, desta forma a desigualdade social e a diferença econômica são cada vez maiores, e atualmente alcançam índices alarmantes, uma enorme parte da população não possui acesso à rede de água e esgoto, à saúde, educação, ao celular ou internet, razão pela qual não conseguem adentrar a era digital.

No artigo sexto da nossa atual "Constituição Cidadã”, constam os chamados Direitos Fundamentais Sociais. São direitos coletivos, destinados a todos de forma indeterminada e indivisível, como a educação, a saúde, a alimentação, o trabalho, a moradia, o transporte, o lazer, a segurança, a previdência social, a proteção à maternidade e à infância, a assistência aos desamparados.

Esses direitos possuem caráter diferente daqueles previstos no artigo $5^{\circ}$, que são os Direitos à Liberdade Individual. Nos Direitos Sociais, os remédios ou as ações judiciais 
provocadas para garanti-los não bastam, por se tratar de situações que precisam ser criadas, normalmente por políticas públicas.

$\mathrm{O}$ atual desafio do direito contemporâneo de delinear a forma de atendimento dos novos direitos sociais, coletivos e indivisíveis, confunde-se com a exclusão digital, advinda da revolução tecnológica, com todas as suas incríveis transformações na vida moderna, calcadas em tecnologias de alto custo, exploráveis comercialmente no mercado privado, sabendo que o Estado não é onipotente para conferir a todos igualdades de direitos sociais e digitais, gerando um futuro incerto à população menos favorecida. É preciso saber se esta será abrangida pelo fenômeno da modernização ou se será definitivamente esquecida, resultando em uma população obsoleta e excluída da sociedade digital.

Frente a esse cenário surgem muitos questionamentos, com a automação e o uso das tecnologias como a inteligência artificial, a tendência é que os trabalhadores necessitem de habilidades e competências específicas e um mínimo de estrutura, como o acesso à internet, sob pena de serem substituídos.

A questão é importante e atual, ficando as escancaras no presente ano de 2020, com o advento da pandemia do coronavírus, milhões de pessoas sem internet, sem celular e sem saber utilizar um aplicativo, muitas até sem cadastro de pessoa física (CPF), o governo brasileiro surpreendeu-se com os invisíveis e não conseguiu pagar a todos o auxílio emergencial.

Sabe-se que a linha de pensamento da Sociedade da Informação está baseada na cultura ocidental que possui valores ligados as doutrinas liberais, como a ideia de respeito aos direitos individuais da propriedade privada, da livre iniciativa econômica, do livre mercado, e das liberdades fundamentais.

A transformação digital, com natural característica capitalista, tem se apresentado como um serviço oferecido em larga escala, o que remete à lembrança do que ocorreu na primeira Revolução Industrial, iniciada na Europa. Naquela época não havia legislação social voltada a integração da população, usada, mas não considerada, leis que somente surgiram após revoluções conhecidas, que colocaram em cheque a nova forma de viver daquela sociedade, fazendo surgir ideologias socialistas, em contraposição ferrenha ao capitalismo.

Não se pode correr o risco de repetir o lado negativo daquela história, não se deve permitir que a era digital seja acusada no futuro, de nos lançar em direção a uma catástrofe social. Seria possível que a transformação digital um dia se voltasse contra a sociedade? 
Os imensos benefícios da era digital não podem ser direcionados somente aos mais favorecidos, mas sim a todo e qualquer cidadão. Não se pode permitir a perda de uma chance de se ter chance, para isso é preciso assegurar de que maneira os direitos fundamentais serão aplicados também na era digital, quando, como e de que forma haverão esforços nesta direção. A questão é saber se os direitos fundamentais garantidos pela Constituição Federal protegem os menos favorecidos também na era digital?

A metodologia de pesquisa foi bibliográfica com abordagem crítica. O método hipotético-dedutivo com abordagem qualitativa e objetivos exploratórios. Os estudos foram embasados pelos pressupostos constitucionais, perpassando pelos aspectos da dialética como contribuição crítica à análise.

\section{DO EXPANSIONISMO JURÍDICO}

A partir da Constituição de 1988, matérias de toda ordem: econômica, tributária, política, previdenciária, financeira, social, dentre tantas outras, foram delimitadas expressamente, o que por si só, denota grande judicialidade.

Em decorrência desta característica positivista, a Constituição possui 114 (cento e catorze) artigos, com uma infinidade de parágrafos e incisos. Além disso, contamos com um grande número de emendas constitucionais, atualmente 107 (cento e sete), número bastante elevado se compararmos com a Constituição dos Estados Unidos, que possui apenas 7 (sete) artigos e 27 (vinte e sete) emendas.

Vivemos na era do pós-positivismo jurídico, ultrapassada a fase do positivismo, que vigorava na época de movimentos como o fascismo e o nazismo e que fazia prevalecer somente o direito isolado, como uma ilha, resultando em consequências nefastas já conhecidas. Hoje sabemos que o direito deve vir acompanhado dos valores, da filosofia moral e ética e da política. É o neoconstitucionalismo com a formação do Estado constitucional, que tem como principais características, de acordo com as lições de Barroso (2006, p, 20):

a) o reconhecimento da força normativa da Constituição;

b) a ascendência da jurisdição constitucional; e

c) o surgimento de uma nova dogmática de interpretação constitucional.

No passado positivista, os princípios só se mostravam necessários quando da existência de lacunas na lei. Atualmente essa concepção foi modificada, ocupando os 
princípios constitucionais, importante papel na busca da justiça, como é o caso do princípio da dignidade da pessoa humana, que atua como valor essencial da vida.

Passou-se a associar às leis, outros valores. Nesse novo contexto a Constituição tornou-se um sistema jurídico aberto, composto por regras e princípios constitucionais. A complexidade desse fenômeno social e jurídico atinge, além da norma, a moral, a ética, a política e diversos outros processos sociais. O processo natural de evolução da sociedade, agora somado às mudanças tecnológicas, conduzem a constante releitura das normas, com consequente inovação de seus significados.

Estamos passando por um processo de aproximação entre justiça e política, tendo em vista que, cada vez mais o judiciário vem garantindo a aplicação de direitos fundamentais em suas decisões, questões afetas à área da saúde, aos costumes e à educação têm sido enfrentadas com essa nova fórmula pelo judiciário, quando provocado, a exemplo da concessão de medicamentos, vaga em escolas, quotas raciais e a criminalização de preconceitos (mandado de injunção n. 4.733).

Sobre a interferência necessária do Judiciário em assuntos constitucionais, Luís Roberto Barroso assevera que:

"Na medida em que o assunto está na Constituição, ele sai da esfera política,
da deliberação parlamentar, e se torna matéria de interpretação judicial.
Então, em uma primeira abordagem, a Constituição de 88 contribui sim para
que o Judiciário tenha um papel muito mais ativo na vida do país. Mas há
um segundo motivo para isso. O atual sistema político brasileiro levou a um
descolamento entre a sociedade civil e a classe política. Há algumas
demandas da sociedade que não são atendidas a tempo pelo Congresso
Nacional. E o que acontece? Nos espaços em que havia demandas sociais
importantes e o Legislativo não atuou, o Judiciário se expandiu".
(BARROSO, 2008).

Sem adentrar à polêmica questão de acusações de ativismo judicial e de práticas como a "máfia" de sentenças judiciais, por não serem objeto do presente estudo, o fato é que o Judiciário, em destaque o Supremo Tribunal Federal, vem garantindo aplicabilidade aos princípios e as normas gerais através da interpretação expansiva da Constituição de 1988. Conforme o Jurista André Karam Trindade, a evolução da jurisprudência brasileira, principalmente quanto ao Supremo Tribunal Federal, compreende três estágios:

1) a fase da ressaca, que se inicia ainda em 1988 - e pode ser caracterizada como o período sucessivo à promulgação da Constituição;

2) a fase da constitucionalização, que começa ainda no final da década de 90 ,

é marcada pelo descobrimento da Constituição e de seus princípios. Os 
tribunais deixam de exercer a função de mero aplicador de leis e, paulatinamente, assumem o papel de intérpretes da Constituição;

3) a fase ativistas, cujo marco inicial pode ser considerado, simbolicamente, a promulgação da Emenda Constitucional $n^{\circ} 457$, em 2004, caracteriza-se por um crescente estímulo voltado à adoção de posturas pró-ativistas.

(TRINDADE, 2012, p. 114-115)

É na terceira fase, segundo o autor, que se encontra o Brasil. A realidade brasileira é marcada pela expansão do protagonismo judicial e na instituição de um ativismo judicial. Vivemos um período de grande transformação, impulsionada pela judicialização da política, influenciada pelo neoconstitucionalismo e pelas teorias pós-positivistas do direito.

Ademais, a Constituição de 1988 atribuiu ao Poder Judiciário, pelo princípio da inafastabilidade, a tarefa de garantir efetividade e respeito aos direitos fundamentais, de maneira a atender aos anseios sociais, através da aplicação da justiça distributiva. Nesta linha de raciocínio, o Supremo Tribunal Federal é considerado o guardião da Constituição Federal.

Em voga, a evolução da sociedade moderna com relevância aos direitos fundamentais, na medida em que são direitos essenciais, básicos para um respeito mínimo à dignidade da pessoa humana.

Os Direitos fundamentais são normas jurídicas auto exigíveis, eles têm efetividade e devem ter eficácia jurídica. O reconhecimento destes requer a intervenção do Estado, ou seja, obrigam o ente estatal a intervir sempre que necessário, para o acesso aos direitos expressos na Constituição.

O autor Dieter Grimm em sua obra Constituição e Política, 2006, afirma que:

"Os direitos fundamentais não são apenas direitos subjetivos de defesa contra o Estado, sendo também princípios objetivos, pelos quais deve se orientar a ordem jurídica, eles produzem para o Estado não só efeito limitador, mas também efeito intimativo."

A atual Constituição Federal elevou os direitos fundamentais à categoria de normas constitucionais, em outras palavras, qualquer norma de ente político que se oponha aos direitos fundamentais, afronta diretamente a Carta Magna, sendo por isso eivada de inconstitucionalidade.

No vácuo da Lei e na ausência de políticas públicas adequadas, para atender aos direitos fundamentais, o Poder Judiciário, no cumprimento de seu papel majoritário e representativo, recebe a atribuição de aplicar o direito de acordo com a interpretação neocontitucionalista e nos limites da própria Constituição. 


\section{DO DIREITO E DAS TECNOLOGIAS}

O Direito possui teorias conflitantes sobre tratar-se ou não de uma ciência, embora possua método científico, pode ser considerado um conhecimento especializado, que determina comportamentos aos seus jurisdicionados, seja concedendo, garantindo, proibindo, obrigando, penalizando ou permitindo determinadas ações. A tecnologia por sua vez, pode ser considerada um instrumento facilitador criado pelo homem com a finalidade de melhorar sua vida, trazendo-lhe conforto, expandindo seu potencial e aumentando suas habilidades e competências.

Assim, o Direito e a tecnologia são criações do homem, sendo que ambos espelham o nível de desenvolvimento de uma nação, seu grau de humanidade.

Também vivem um grande paradoxo: expandir-se e desenvolver-se em prol de uma sociedade justa e igualitária, que seja moderna, pujante e globalizada, ao mesmo tempo em que consigam promover a inclusão e o atendimento de todos os cidadãos, indistintamente, neste sentido:

\footnotetext{
As inovações sociais são igualmente importantes para a implantação de inovações tecnológicas. A relação com as inovações na tecnologia - como as vinculadas aos computadores e internet em geral - precisa ser apreendida, pois especialmente as pessoas mais idosas têm problemas com elas. São exemplos da necessidade de interação entre as inovações tecnológicas e as inovações sociais, o teletrabalho e o telediagnóstico médico.

(...)

Se uma inovação convém ou não ao bem comum é questão frequentemente controversa. Por exemplo, a energia atômica, a engenharia genética ou progresso com base em inovações em pesquisas com células-tronco - todos são campos disciplinares controvertidos em muitas sociedades.

(MENDES; SARLET; 2015)
}

Sabe-se que o direito objetiva buscar a aplicação da Justiça Geral, aquela justiça social que, segundo Aristóteles, é a virtude, e segundo Tomás de Aquino, a que tem por objetivo o bem comum. $\mathrm{O}$ direito, dentro das regras, deve decidir, eliminar os conflitos o mais brevemente possível e, sem sistemas informatizados, atualmente seria impossível.

A tecnologia busca o avanço e o progresso seguindo regras de segurança e confiabilidade, dentro de princípios éticos da iniciativa privada, baseados em doutrinas liberais de livre mercado, com a ideia de respeito aos direitos individuais da propriedade privada, e o desenvolvimento do espírito empreendedor e competitivo. 
O empreendedorismo é a arma da tecnologia, e no Brasil novos empreendedores surgem a cada dia, com novas ideias que resultam em grandes negócios e empresas. As redes sociais são importantes campos, utilizadas para as mais variadas estratégias, o universo digital é riquíssimo em possibilidades.

Sobre essa questão, o autor David Rogers, em sua obra Transformação Digital Repensando seu negócio, mencionando o gatilho que permite as transformações tecnológicas, preleciona:

"A transformação digital não tem a ver com tecnologia - tem a ver com estratégia e novas maneiras de pensar. Transformar-se para a era digital exige que o negócio atualize sua mentalidade estratégica, muito mais que sua infraestrutura de TI". (ROGERS, 2017)

O autor é categórico: a transformação digital deve ocorrer antes no modo de pensar do indivíduo, no seu entendimento enquanto cidadão que integra a sociedade, sua forma de ver o mundo e a decisão de como quer encarar seus negócios, suas dores e as dores de seus clientes, ou seja, na era digital o homem precisa primeiramente transformar a si mesmo.

É a mudança de mentalidade (mindset) que proporciona as condições para a modernização, e posteriormente, entra a tecnologia para efetivá-la. Rever métodos, processos, entender o seu consumidor, possibilitam melhores condições para enfrentar os desafios da era digital, traçando novos rumos, inovando de acordo com o processo de transformação da sociedade.

Nesta linha de modernização voltada ao Judiciário, foi lançado em 21 de junho de 2011, o Processo Judicial Eletrônico (PJe). Um sistema totalmente eletrônico de processo judicial através de softwares. O PJe é uma plataforma digital desenvolvida pelo Conselho Nacional de Justiça, em parceria com os Tribunais de Justiça e com a participação de outros órgãos, como o Conselho Nacional do Ministério Público, Defensorias Públicas e a Ordem dos Advogados do Brasil.

Posteriormente, o processo judicial eletrônico foi estendido e já atende aos diversos segmentos do Poder Judiciário brasileiro: a Justiça Militar, Eleitoral, do Trabalho, Estadual e Federal, além dos órgãos públicos como Receita Federal, Ministério Público do Trabalho e as Procuradorias Federais e Estaduais.

A partir de então, surgiram inúmeras tecnologias a favor do direito, com grande desburocratização e melhora na gestão de grandes volumes de processos, que além de alterar completamente o cenário do então combalido sistema judiciário, que estava à beira do 
colapso, o processo eletrônico permitiu que todos os profissionais do Direito maximizassem seu tempo em atividades de cunho intelectual.

Destaca-se superficial e brevemente algumas destas tecnologias, como a inteligência artificial, que pouco a pouco invade todas as áreas de produção e serviços, especialmente na área do direito. No ano de 2018 entrou em funcionamento o Projeto VICTOR, que utiliza Inteligência Artificial para aumentar a eficiência e a velocidade de análise dos processos distribuídos no STF, foi desenvolvido em parceria com a Universidade de Brasília - UnB.

O Big, data revolucionou o poder judiciário e é conhecido pela alta capacidade de captação e armazenamento de dados, com as técnicas de análise, como volumetria e jurimetria, preciosos para alcançar melhores resultados. $\mathrm{O}$ big data faz o armazenamento de uma imensa quantidade de dados em grande velocidade.

A jurimetria é ligada a técnicas de estatística aplicada ao direito e permite uma análise direta do resultado de processos e decisões judiciais, identificando padrões de varas e Juízes, possibilitando com o conhecimento dos dados, que o profissional da área consiga maiores e melhores resultados.

Não poderia ficar de fora dos destaques a revolução dos escritórios de advocacia. Grandes ou pequenos, em maior ou menor grau, todos se rendem às novas tecnologias. Atualmente, as tecnologias exponenciais que estão dando mais agilidade ao trabalho dos advogados são ligadas ao Big Data, Inteligência Artificial e à jurimetria.

As inovações tecnológicas não são voltadas somente ao direito, pelo contrário, são destinadas à vida moderna como um todo, trabalho, estudos, lazer, transporte, etc. Veja-se a transformação digital na área da saúde, que também traz novidades nos mais diversos setores. A prevenção de doenças e os tratamentos mais complexos estão cada vez mais automatizados.

Não obstante, os problemas da saúde pública no país, a questão dos avanços tecnológicos revoluciona a medicina, facilitando o trabalho dos profissionais e beneficiando os pacientes.

A transformação digital na educação brasileira também é uma grande tendência e em breve será uma realidade. A afirmação se dá pelo fato das tecnologias terem alterado o cotidiano dos jovens, a comunicação entre eles, a velocidade com que se relacionam e aprendem; empurrando o modelo tradicional de ensino a uma grande crise, pois não desperta mais o interesse dos alunos. Pensando nisso, muitas instituições de ensino, principalmente as privadas, têm apostado em ferramentas inovadoras para tornarem as aulas mais atraentes, são 
as metodologias ativas com o uso das tecnologias. Aplicativos gratuitos do google, como mentimeter para pesquisas de opiniões em sigilo; editores de textos; azscreen recorder para gravar vídeos; kahoots (games); mozaik (explorer em 3D); joomag; jamboard, entre outros.

Em que pesem as resistências dogmáticas da educação tradicional, as novas formas de pensar a educação em que o aluno é o centro do processo de ensino-aprendizagem, mantendo uma relação horizontal com o professor, na busca de habilidades e competências, fazem das novas tecnologias armas poderosas.

A rede mundial de computadores "internet" cresce a níveis imensuráveis. A internet proporcionou o surgimento de novos paradigmas sociais na área da informação. Comunicação on-line, abreviaturas e a utilização de memes, a profissionalização de pontos de vista com o surgimento dos influenciadores digitais, e a expansão do comércio eletrônico em geral.

São várias as inovações de multiplataformas de gerenciamento de produtos e serviços, vídeos conferencias; plataformas web de aplicação de cursos on-line, plataformas gratuitas como meet, zoom, hangouts; aplicativos como whatsapp; e-mail; instagram; facebook; google acadêmico; e-books; blogs; entre tantos outros.

Não se pode esquecer de destacar as Startups, que são empresas emergentes, cujo objetivo principal é desenvolver ou aprimorar um modelo de negócio, preferencialmente disruptivo e exponencial, e são agentes empreendedores por natureza.

O experiente estrategista de mídias sociais e tecnologia Paul Armstrong, autor do livro Dominando as tecnologias disruptivas, citando Tom Goodwin (2015), expõe o nível estratosférico das inovações, uma maneira de ver como a disrupção atua e afeta negócios estabelecidos, afirma que:

"A Uber, a maior empresa de táxis do mundo, não tem veículos. O Facebook, dono da mídia mais popular do mundo, não cria conteúdo. O Alibaba, varejista mais valioso, não tem estoque. E o Airbnb, maior fornecedor de hospedagem do mundo, não tem propriedades". (ARMSTRONG, 2019)

Enfim, daqui para frente o mundo será assim, globalizado e plugado, transformandose numa enorme comunidade, é a sociedade em rede, com suas ferramentas utilizadas na troca e acesso a uma vastidão de informações e tecnologias.

A iniciativa privada deve se adaptar, mudar seu mindset e inserir-se na nova realidade, já ao Estado brasileiro cabe a tarefa de adequar-se aos novos tempos e propiciar mecanismos para que a sociedade receba bem a tecnologia e a informação digital, da maneira 
mais ampla e democrática possível. A tecnologia é um veículo poderoso para introduzir mudanças e as possibilidades são imensas e até imprevisíveis. Não deve ser utilizada apenas para auxiliar na redução de custos e no aumento de lucros, mas principalmente como ferramenta para aumentar a potencialidade das pessoas como um todo.

\section{DO ACESSO A INTERNET COMO DIREITO FUNDAMENTAL}

$\mathrm{Na}$ era digital, as maiores fontes de riqueza são a comunicação, o conhecimento e a tecnologia, na chamada sociedade da informação eles são a fonte do Poder Político, como outrora foi a terra na sociedade agrícola e o capital financeiro na sociedade industrial.

Sobre a questão saber tecnologia, com poder de mudar de forma definitiva a história da Humanidade, o autor Pierre Levy em sua obra Cibercultura, ensina:

"No ciberespaço, o saber não pode mais ser concebido como algo abstrato ou transcendente. Ele se torna ainda mais visível - e mesmo tangível em tempo real - por exprimir uma população. As páginas da Web não apenas são assinadas, como as páginas de papel, mas frequentemente desembocam em uma comunicação direta, por correio digital, fórum eletrônico ou outras formas de comunicação por mundos virtuais como os MUDs ou os MOOs" (LÉVY, 1999).

A maior fonte de informação nesta nova era é a internet, seja pela facilidade de uso, seja pelo conteúdo vasto e variado. Os sites de busca possuem toda gama de informações aptas a serem transformadas adequadamente em conhecimento, de fato, como imaginar o mundo hoje sem internet?

Nosso cotidiano foi invadido pelas redes sociais, e-mails, whatsapp, facebook, instagram, vídeos chamadas, relacionamentos eletrônicos, comércio eletrônico, operações bancárias, enfim, abrange tudo o que nos rodeia. É possível, com apenas um clique, interagir com pessoas de todo o planeta, a qualquer momento, a distância no mundo da internet simplesmente não existe.

Frente a esse cenário e, em um país com tamanhas diferenças sociais, torna-se de suma importância fazermos uma reflexão propositiva acerca da acessibilidade, com o reconhecimento do acesso à internet como direito fundamental, promovendo a inclusão digital, conforme sustenta Maria Thereza Pillon Ribeiro (2011, p. 03):

A inclusão digital deve ser vista sob o ponto de vista ético, sendo considerada como uma ação que promoverá a conquista da "cidadania 
digital”, a qual contribuirá para uma sociedade mais igualitária, com a expectativa da inclusão social. [...]

Inclusão digital é o acesso à informação que está nos meios digitais e, como ponto de chegada à assimilação da informação e sua re-elaboração em novo conhecimento, tendo como consequência desejável a melhoria da qualidade de vida das pessoas.

Ocorre que no Brasil o acesso à internet não é para todos, na TV Cultura através do jornal da tarde, foi realizada uma entrevista pública com o pesquisador Fábio Sene, coordenador de projetos de pesquisa, ele contou que num estudo de 2018 , cerca de $70 \%$ da população brasileira é usuária da internet, mas que 30\% desta fatia simplesmente não tem nenhum acesso, ressaltando a importância, não só do acesso básico, mas da qualidade dele para populações menos favorecidas das áreas vulneráveis, zonas rurais, pessoas da classes D e E de faixas etárias mais altas (idosos).

Neste sentido, a falta de acesso à internet aumenta o abismo social brasileiro, pior que a conhecida diferença de classes com a tradicional exploração de mão-de-obra desqualificada; talvez, gerando no futuro a exclusão definitiva dos menos favorecidos, pois os mesmos podem se tornar absolutamente desnecessários e esquecidos, aponta Pérez Luño:

A Internet está criando novas formas de desigualdade entre os "info-ricos" e "info-pobres", ao estabelecer discriminações graves ao acesso e utilização de informações entre o Norte e o Sul, onde a falta de equipamentos irá condenar à marginalização milhões de pessoas. (LUNO, 2003, p. 90-91)

Veja-se o exemplo dos dias atuais com o enfrentamento da pandemia do coronavírus, que colocou toda a população em isolamento social. Em um país tão desigual, os mais favorecidos, que estão nas escolas particulares com toda estrutura de ensino, conseguem se adaptar ao método $\mathrm{EaD}$, que socorre a todos, para não haver prejuízos e perda total do ano letivo, assim como, para preparação para o ENEM. Todavia, os menos favorecidos das escolas públicas, não têm a mesma sorte, por falta de estrutura e de preparo das escolas, dos professores e dos alunos.

Ainda é um desafio garantir o acesso de toda esta gama de tecnologia a todos indistintamente, sob pena de desigualdade de oportunidades, pois o acesso a informação é pressuposto para qualquer tentativa de desenvolvimento social, conforme afirma o Ilustre Professor Horácio Wanderlei Rodrigues:

"A desigualdade material, em contraste com a igualdade formal prevista no ordenamento jurídico, acaba por colocar o sujeito mais pobre em situação de 
desvantagem no desenvolvimento do processo" (RODRIGUES, 2008, p. 252).

Bem, por se tratarem de recentes transformações tecnológicas, o Direito ainda conta com poucas normas que regulamentam a matéria, está nascendo o chamado direito digital, com o Marco Civil da Internet (lei n. 12.965/14) e a chamada Lei Carolina Dieckmann (lei n. 12.737/12), são dois exemplos de recente legislação. A Lei Geral de Proteção de Dados (LGPD) é o mais novo exemplo de legislação sobre transformações tecnológicas.

Há vasto campo para o trabalho legislativo, a tecnologia invadiu o direito, a saúde, a segurança, o transporte, o entretenimento, a educação e tantos outros setores da vida. Em voga grandes discussões jurídicas no embate entre tecnologia e o Direito, abertos os debates para fixação dos critérios e as delimitações dos temas.

Imperativo que se pense como evitar a exclusão digital, conferindo igualdade de condições para que toda a população tenha acesso a tecnologia, o acesso à internet é um mínimo que obrigatoriamente deve ser garantido a todos. Não obstante as inovações tecnológicas terem viés privado, despiciendo dizer que a população pobre e necessitada não tem nem terá acesso à era digital, se não houver o suporte do Estado. Não é questão de não querer, mas de não poder; de não terem condições sequer de conhecimento das novidades que aqui se tratou.

De forma que, a internet precisa ser incluída na Constituição Federal em seus artigos $5^{\circ}$ ou $6^{\circ}$, como direito fundamental, seja junto aos direitos e garantias individuais ligados à pessoa humana, seja junto aos direitos sociais coletivos, difusos e indivisíveis da coletividade, ao lado da saúde e educação e os demais direitos fundamentais expressos.

Importante observar que já vemos o esforço de alguns pesquisadores do Direito debruçados sobre importantes questões decorrentes da tecnologia, temas como células tronco, transgênicos, engenharia genética e outros ligados à evolução científica, que causam preocupação no mundo jurídico; mas não podemos nos esquecer do básico, pois é nele que reside a verdadeira transformação social, não se pode perder a oportunidade de evoluirmos enquanto seres humanos.

$\mathrm{O}$ acesso à internet, como direito fundamental, assim como o direito à saúde, à educação e ao lazer, precisa ser reconhecido como justa inclusão digital. O direito à internet e consequentemente o acesso a informação e tecnologia deve ser prioridade, para que se dê a 
oportunidade ao indivíduo de evoluir junto à sociedade digital, a internet precisa ser democrática.

Portanto, a internet deve ser um espaço aberto e democrático para pobres e ricos, sem distinção de raça, cor ou sexo. Deve ser um território livre, sem fronteiras e sem entraves sociais.

A professora Regina Belluzzo escreveu sobre a transformação digital e a competência em informação (Coinfo), trouxe uma reflexão bastante interessante acerca da era digital e a transformação da sociedade em todas as suas vertentes, e a necessidade da disseminação da aquisição de Competência em informação para os brasileiros em geral; divulgando a agenda de desenvolvimento da ONU, trabalhada na conferência Rio mais 20 para 2030 ,para a busca do cidadão no século XXI, com pensamento crítico sobre a informação para: a) saber localizar e acessar a informação; b) saber que processos efetuar para compreender a informação e utilizá-la.

Diz que a Coinfo deve ser compreendida como um direito fundamental da pessoa humana, levantando a seguinte questão:

É sabido que muitas pessoas e organizações não dominam plenamente os seus recursos de TIC ou não estão sendo educadas e formadas com o seu uso, e esse fato as tornam significativamente carentes de desenvolvimento de novas competências e habilidades que as tornem mais exigentes e críticas no que diz respeito às possibilidades de verem suas necessidades atendidas por esse meio. É preciso estar informado e ter consciência do lado luminoso e do lado sombrio da revolução digital. Depois é preciso aceitá-los. Saber inter-relacionar a realidade digital (pensar na economia digital global) à realidade das populações (agir na economia física local) será uma decisão a ser tomada, cuja responsabilidade é de todos os atores sociais. (BELLUZZO, 2019, p. 13)

O foco de seu artigo cientifico é promover a reflexão à luz dos cenários atuais das transformações sociais, refletindo especificamente acerca da falta de habilidades e capacidades, tão necessários para os desafios que se fazem presentes ante à multidiversidade cultural e à complexidade de acesso e uso da informação encontrada nos novos instrumentos, decorrentes da transformação digital.

Para Belluzzo ao tratar das competências necessárias para os desafios da era digital:

A evolução da Internet e sua utilização em larga escala, permitindo a existência de verdadeiras "auto-estradas de informação", com certeza está havendo a remoção de inúmeras barreiras no acesso e uso da informação, permitindo que as pessoas acessem diretamente aos documentos 
eletrônicos, independentemente de sua localização e sem intermediações. Entretanto, há um paradoxo inserido nesse particular, em especial no contexto brasileiro muitas outras barreiras estão emergindo em contrapartida, devido ao custo econômico-financeiro dessa tecnologia e também do despreparo das pessoas em face da maior complexidade em relação aos processos de utilização adequada das fontes eletrônicas e ao aumento exponencial de informação que, muitas vezes, não tem a qualidade necessária, exigindo uma maior reflexão crítica sobre sua pertinência, relevância e confiabilidade (BELLUZZO, 2005, p.33).

Numa definição de competência em informação promovida pela UNESCO (2016, p.9) é importante destacar:

"Conjunto que empodera os cidadãos, permitindo que eles acessem, busquem, compreendam, avaliem e usem, criem e compartilhem informações e conteúdos midiáticos em todos os formatos, usando várias ferramentas, de forma crítica, ética e eficaz, com o objetivo de participar e de se engajar em atividades pessoais, profissionais e sociais." (UNESCO, 2016, p.9).

A Constituição Federal de 1988 assegura aos cidadãos o direito fundamental da liberdade de informação, prevendo em seu artigo $5^{\circ}$, no inciso XIV que: "é assegurado a todos o acesso à informação e resguardado o sigilo da fonte, quando necessário ao exercício profissional". Não obstante, o artigo ser muito utilizado para a imprensa ao tratar do direito de informação e o sigilo da fonte, a principal tutela é o direito de todos à informação.

No inciso XXXIII do mesmo artigo, a CF determina: "todos têm direito a receber dos órgãos públicos informações de seu interesse particular, ou de interesse coletivo ou geral, que serão prestadas no prazo da lei, sob pena de responsabilidade, ressalvadas aquelas cujo sigilo seja imprescindível à segurança da sociedade e do Estado". Neste caso, consta o direito de receber informações dos órgãos públicos.

No ordenamento jurídico infraconstitucional, verifica-se a existência da Lei 12.965/14 (Marco Civil da Internet), que dispõe sobre direito de acesso à Internet como um direito de todos e essencial ao exercício da cidadania, bem como, define questões técnicas da internet:

Art. $4^{\circ}$ - A disciplina do uso da internet no Brasil tem por objetivo a promoção:

I - do direito de acesso à internet a todos;

II - do acesso à informação, ao conhecimento e à participação na vida cultural e na condução dos assuntos públicos;

III - da inovação e do fomento à ampla difusão de novas tecnologias e modelos de uso e acesso; e

IV - da adesão a padrões tecnológicos abertos que permitam a comunicação, a acessibilidade e a interoperabilidade entre aplicações e bases de dados. 
Art. $7^{\circ} \mathrm{O}$ acesso à internet é essencial ao exercício da cidadania, e ao usuário são assegurados os seguintes direitos:

I - inviolabilidade da intimidade e da vida privada, sua proteção e indenização pelo dano material ou moral decorrente de sua violação;

II - inviolabilidade e sigilo do fluxo de suas comunicações pela internet, salvo por ordem judicial, na forma da lei;

III - inviolabilidade e sigilo de suas comunicações privadas armazenadas, salvo por ordem judicial;

IV - não suspensão da conexão à internet, salvo por débito diretamente decorrente de sua utilização;

V - manutenção da qualidade contratada da conexão à internet;

...

XI - publicidade e clareza de eventuais políticas de uso dos provedores de conexão à internet e de aplicações de internet;

XII - acessibilidade, consideradas as características físico-motoras, perceptivas, sensoriais, intelectuais e mentais do usuário, nos termos da lei; $\mathrm{e}$

XIII - aplicação das normas de proteção e defesa do consumidor nas relações de consumo realizadas na internet.

Vale mencionar que já houve quem notasse a indiferença a essa questão do acesso à internet, com a Proposta de Emenda à Constituição no 479/2010 e 6/2011 para a inserção desse direito no artigo $5^{\circ}$ da Constituição Federal. Nas propostas foram ressaltados o caráter econômico e a preocupação com a exclusão social, defendidas por outros países, e desenvolvidos pela ONU, mas as propostas foram arquivadas.

A vida está em rede, o debate precisa ser travado na esfera pública e privada, o planejamento de políticas públicas, que integrem o uso de tecnologias com acesso a todos indistintamente, especialmente aos menos favorecidos, é urgente em uma sociedade que precisa partir efetivamente para a era digital.

O acesso à Internet como um direito social, previsto na Carta Magna e, portanto, traduzindo-se em uma obrigação do Estado brasileiro para com seu cidadão, permitirá, na ausência do Estado, promover políticas públicas, que sejam exigidas judicialmente para garantia de inclusão.

Não há dúvida de que o reconhecimento do acesso à Internet como um direito fundamental trará relevantes benefícios, para garantir a proteção dos direitos da população, para que possam fazer parte dos avanços tecnológicos. A tecnologia é um primoroso instrumento para o progresso da nação, e o direito o veículo poderoso que poderá democratizá-la, de forma mais justa e igualitária possível, respeitando as diferenças e promovendo a isonomia. 


\section{CONCLUSÃO}

A quarta revolução industrial é uma realidade no Brasil, advinda das necessidades humanas e sociais, caracterizada pelas altas tecnologias, IA, Big data, Internet das Coisas, software em nuvem, robótica, enfim, tecnologias disruptivas e exponenciais decorrentes da iniciativa privada e do empreendedorismo. A era digital altera o modo de vida como um todo, dos costumes ao entretenimento, das profissões aos estudos; mas não é disponível a todos pois exige competências e habilidades específicas, e um mínimo de estrutura.

O Direito contemporâneo tem nos princípios constitucionais a base da hermenêutica comprometida com a justiça, com um papel fundamental para promover a inclusão digital indistintamente. É papel essencial do Estado Democrático de Direito o desenvolvimento de toda a sociedade na busca da paz e justiça social.

São incipientes as iniciativas legais infraconstitucionais para garantir o acesso à internet à população menos favorecida, que hoje conta com pelo menos $30 \%$ das pessoas sem nenhum acesso à rede mundial, tendo o coronavírus escancarado esse abismo social.

Não resta dúvida que o reconhecimento pela Constituição Federal do acesso à internet como um direito fundamental trará inúmeros benefícios a todos, possibilitando a evolução da sociedade e refletindo o grau de evolução do país; em que pese seus efeitos não serem automáticos, sendo necessária a atuação dos três poderes, e o planejamento de políticas públicas de maior abrangência, para que, além do acesso à internet, também proponham ações dirigidas a criar oportunidades, destinadas à aquisição de competências e habilidades.

\section{REFERENCIAS}

ARMSTRONG, Paul. Dominando as tecnologias disruptivas: aprenda a compreender, avaliar e tomar melhores decisões sobre qualquer tecnologia que possa impactar o seu negócio. 1 ed. São Paulo: Autêntica Business, 2019.

BARROSO. Luís Roberto. Constituição, democracia e supremacia judicial: direito e política no brasil contemporâneo. Revista Jurídica da Presidência, Brasília, v. 12, n. 96, fev/mai. 2010

BARROSO, Luís Roberto. Quando a política vai mal, o judiciário toma conta. In: Jus Brasil Notícias. Entrevista à revista Consultor Jurídico em 21.09.2008. Disponível em: 
http://www. jusbrasil.com.br/noticias/112078/entrevista-luis-roberto-barroso-advogadoconstitucionalista. Acesso em: 20.06.2020.

BELLUZZO, Regina Celia Baptista. Transformação digital e competência em informação: reflexões sob o enfoque da Agenda 2030 e dos Objetivos de Desenvolvimento Sustentável; Revista: Conhecimento em Ação, Rio de Janeiro, v. 4, n. 1, jan/jun. 2019

GRIMM, Dieter. Constituição e Política. Del Rey Internacional. Belo Horizonte. 2006.

LÉVY, Pierre. Cibercultura. São Paulo: Editora 34, 1999.

LIPOVETSKY, Gilles. Da leveza: rumo a uma civilização sem peso. Tradução de Idalina Lopes. São Paulo: Barueri, 2016.

LOPES, José Reinaldo de Lima. Direito subjetivo e direitos sociais: o dilema do judiciário no estado social de direito, Editora Malheiros, 1994.

MENDES, Gilmar Ferreira, SARLET, Ingo Wolfgang, COELHO, Alexandre Zavaglia P. Direito, Inovação e Tecnologia. São Paulo: Saraiva, Vol. 1, 2015. LUÑO, Antonio Enrique Pérez. Ciberciudadaní@ o ciudadaní@.com?. Barcelona: Gedisa, 2003.

RIBEIRO, Maria Thereza Pillon. Inclusão Digital e Cidadania. 2011. Disponível em: < http://www2.faac.unesp.br/blog/obsmidia/files/Maria-Thereza-Pillon-Ribeiro.pdf> Acesso em: 19 junho 2020.

RODRIGUES, Horácio Wanderlei. Acesso à justiça no Estado Contemporâneo: concepção e principais entraves. In: SALES, Lília Maia de Morais; LIMA, Martonio Mont'Alveme Barreto (Org). Constituição, Democracia, Poder Judiciário e Desenvolvimento - Estudos em homenagem a José de Albuquerque Rocha. Florianópolis: Conceito, 2008. p. 237-276

ROGERS, David L. Transformação Digital: Repensando o seu negócio para a era digital, editora São Paulo. 2017.

Disponível: $<$ https://books.google.com.br/books?id=emkvDwAAQBAJ\&printsec=frontcover

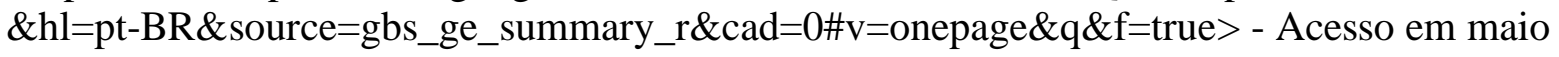
2020.

TRINDADE, André Karam; GUBERT, Roberta Magalhães. 20 anos de constitucionalismo democrático: avanços, retrocessos e novos desafios em terrae brasilis. Revista do Instituto de Hermenêutica Jurídica, Porto Alegre, n. 6, pp. 7-14, 2008.

UNESCO. Marco de avaliação global da alfabetização midiática e informacional: disposição e competências do país: resumo executivo. Genebra: UNESCO, 2016. 